\title{
The Use of Codenames Game to Help Students in Learning Vocabulary
}

\author{
Inggil Tiara Octaviana \\ IAIN Pekalongan, \\ inkgelvanqu@gmail.com \\ Rayinda Eva Rahmah \\ IAIN Pekalongan, \\ rayindanda@gmail.com \\ Dewi Puspitasari \\ IAIN Pekalongan \\ dewipuspitasari@iainpekalongan.co.id
}

\begin{abstract}
English department students of IAIN Pekalongan have many shortcomings in memorizing vocabulary. This is evidenced by our observations when students are speaking in front of the class. Sometimes, students are confused about conveying information they want to deliver because they are constrained by a lack of memorization of vocabulary. The situation happens when students must use English in active discussions. So far, the students tend to memorize vocabulary. Besides that, vocabulary books are less effective and less interesting because it only relies on the use of language skills. One way to learn vocabulary in a simple way is through codenames game. This game provides many vocabularies that must be guessed by the players in a team. Then, another player should describe the word to be guessed. So, this research's questions are how the codenames game is implemented due to learning English in a fun way. By reflecting the question, the purpose of this research is to provide information on the implementation of codenames game which helps English department students of IAIN Pekalongan enrich and build their vocabulary through a fun way using game cards. Based on our observation, the result showed that applying the codenames game could enrich the students' vocabularies, be an alternative entertainer so that the students do not easily get bored, and strengthen the students' memory. Thus, it can be concluded that playing codenames game promotes a helping way to enrich and build the students' vocabulary.
\end{abstract}

\section{Introduction}

Vocabulary is central to language teaching and learning. It plays an important role in the four language skills, which gives a better contribution to the learners to perform
ARTICLE HISTORY

Received 23 June 2019 Accepted 30 September 2019

\section{KEYWORDS}

Codenames game; memorizing; vocabulary 
or practice their skills. Words are a base form of a sentence which is the core means of communication, either verbally or written. Good mastery of vocabulary will enable someone to communicate with others effectively and vice versa. This is in line with what linguist, David Wilkins says that "Without grammar very little can be conveyed, without vocabulary nothing can be conveyed" (Thornbury, 2002:13). It illustrates clearly how important is the contribution of vocabulary toward communication. Swan and Walter (Thornbury, 2002: 14) in the forewords of Cambridge EnglishCourse written in 1984 also emphasize on the vital roles of vocabulary in learning English context. They stated that "vocabulary acquisition is the largest and most important task facing the language learners."

The students consider that the English lesson is a difficult subject. They particularly are unable to know the meaning of daily vocabulary. Learning vocabulary needs a strong effort due to the requirement of understanding, producing, and manipulating the words. Without doing any attempts to learn vocabulary, so how the students use them to learn another part of English lessons like grammar, tenses, or even comprehend a whole text? This kind of situation is also performed by some English department students of IAIN Pekalongan which is evidenced by the observation when students were speaking in front of the class.Sometimes, students seem confused in conveying the ideas that they want to say because they are constrained by a lack of memorization of vocabulary. They tend to be hesitant in what to say next and have less confident. The same thing also happens in a situation when students are required to actively use English in a discussion forum. Having discussed to use English in a classroom activity affected that the students commonly only use the technique of memorizing. Each student has already been given a minibook to memorize vocabulary, but it couldn't bring any contribution to students' vocabulary development. The boredom and forgetfulness which drive the students' feeling could not be avoided due to the use of a traditional way in the form of a minibook.

Considering the reason above, we want to highlight a solution especially to help students build and enrich their vocabulary mastery. The solution is by using a technique to facilitate learning vocabulary which its name is the Codenames Game.The codenames game is a vocabulary game that is not played by simple rote memorization as Celce-Murcia (2001) contends, "it is important that new vocabulary items be presented in rich contexts to provide clues to meaning and that students be given multiple exposures to items they should learn."

The Codenames Game was inspired by research presented in the $1^{\text {st }}$ COTEFL International Conference by Soviyah and Nur Rifai Akhsan from Ahmad Dahlan University entitled "Boosting Students' Vocabulary through Index Card", but the Codenames Game which we made is a modification from the real codenames games. This game card offers a challenge that motivates the students to enthusiastically play the game. The game involves two teams. Each team has a Spymaster which aims giving clues by pointing to multiple words on the board. While another player on a 
team attempts to guess their team's words while avoiding the words of the other team. Within playing this game, much opportunity is widely offered for the students to describe and find the appropriate vocabulary from guessing.Besides, playing this game is good at helping students build a large vocabulary in the English teachinglearning process.The students will find this game fun, relaxed and challenged by memorizing the vocabulary in a different way.

Based on the background above, the writers would conduct a study to help students build a large vocabulary using a cards game. So, the writers decide to conduct a study entitled "THE USE OF CODENAMES GAME TO HELP STUDENTS IN LEARNING VOCABULARY."

\section{Literature Review}

\section{What is a game?}

There are numerous studies have investigated on understanding learners' vocabulary learning strategies and techniques using the game. Games assist students to actively involve and ask more participation in the learning process. According to Celce-Murcia (1989) games are fun and nearly everyone would agree that if learning can be made enjoyable for students, the students will learn more. By using games, the students are expected to retain the words in enjoyable learning.

Reza, Mohammad, and Sayed (2015) reported a study on the effect of game tic tac toe and flashcards on zero beginners' vocabulary learning. The results indicated that flashcards and tic tac toe games as educational tools for training had more positive influence than traditional. It is indicated that teaching through games had a positive effect on zero beginners' vocabulary learning and they made the teaching-learning process enjoyable, alive, visible, attractive and motivating.

Similarly, Robert and Laura (2017) conducted a study on the effective strategies for teaching vocabulary: an introduction to engaging cooperative vocabulary card activities. The purpose of the paper is to describe how learners made vocabulary cards help students initially learn the lexical items found on the NGSL and other important special-purpose vocabulary lists. Besides, they present a variety of engaging cooperative learning activities that reinforce the learning of these lexical items, thereby overcoming the lack of recycling in most EFL textbooks. These exciting activities have been well received by learners across levels in a variety of EFL contexts.

While there was a study conducted by Jahanbakhsh and Azin (2014), which utilized the digitized and non-digitized flashcards served as learning tools as evaluating the vocabulary gain of advanced English learners. The use of 
mobile phones and online website are applied in this study as part of the advantages to represent a language learning resource worthy of further investigation. The result was found that mobile phones have made effective vocabulary learning which proved by the vocabulary gain of students using mobile flashcards was found higher than paper flashcard users.

Brigitta (2016) investigated the use of flashcards in teaching vocabulary at fourth-grade students of SDN Sukosari 02 Dagangan Madiun. The application of flashcards makes the students feel relax and create an interesting atmosphere. Therefore, the students can memorize the presented vocabulary easily by focusing their attention on the lesson. The result revealed that the implementation of the flashcards gives a valuable contribution to students' vocabulary mastery. It could be said that most students are interested in using flashcard when they are learning English. The students say that flashcards can motivate them because the pictures are interesting and the language in use it easy to understand.

Luu Trong Tuan (2012) examined whether games influence young learners' vocabulary recollection in Vietnam. This study applied two classes namely an experimental group that was exposed to games in recollecting vocabulary, and a control group without any games included. Therefore, the experimental group surpassed the control one in recollecting vocabulary during the immediate retention stage and the delayed retention stage. It can be said that from this study, the implementation of games can be an effective method to reinforce vocabulary recollection.

However, only a few studies have empirically investigated the effectiveness of guessing words assisted vocabulary. The previous studies mainly focused on the reinforcement of a collection vocabulary using card games. So, the focus of this study is the implementation of card games in guessing vocabulary that should be played by the players in a team. The students who are most of the young learners pass good meaning interpretation creatively, and learn directly the vocabulary competing with another team using codenames game.Through this game, the students actively build the number of vocabulary in a more fun, relaxed, and challenged way.

\section{Why Should Game Be Highly Recommended to Play in the Classroom?}

Games belong to social life. Every learner without any doubt likes to play games. Games could activate the way students learn English. It can be proofed by numerous scholars conducting the research (Chan \& Lin, 2000; Jiang, 2008; Kuo, 2008; Robinson, 1960; Zheng,2008) which have pointed out that games are useful for children involved in the learning of English since 
games can strengthen students'motivation and self-confidence. In addition, according to Skinner's theory, playing games can be presented as a kind of prize after learning which allows teachers to motivate learners to step forward (Pound, 2005). Concerning the meaning of playing games, it is clear that games cannot be ignored in learning a foreign language, especially in the English classroom. Take for an example is if students are aware that they are going to play vocabulary games after they learn either grammar structure or other skills, they will look forward to participating in that activity by applying things that they have previously learned with greater motivation. Moreover, the significance of playing the game in the classroom is also supported by Piaget due to its contribution to the development of problem-solving, creativity, and communication, which happens naturally in the process of playing games (Slavin, 2006).

Regarding with playing games in a classroom, from the affective filter hypothesis of the natural approach proposed by Krashen which views that "learners with high motivation generally do better, and learners with selfconfidence and a good self-image tend to be more successful" (as cited from Richards \& Rodgers, 2001, p. 183). This concept is also relevant to the use of games in teaching English, which aims to boost children's motivation and confidence which can then promote higher levels of English learning (Wang, Shang \& Briody, 2011).

There are many good ideas about English teaching. Among these, using games in English class is the one which is most easily accepted by students. Further, games provide a very useful and helpful aspect of the communicative method. It is clearly known that game is an activity providing entertainment or amusement and a competitive activity or sport in which players contend with each other according to a set of rules. Moreover, a game is an activity carried out by co-operating or competing decision-makers, seeking to achieve, within a set of rules, their objectives (Rixon 1981). So, it can be said that the game is an activity that both the teacher and students enjoy doing. In addition, game concerns on student-centered as appealing as playing in the playground.

Using games in the English class can get students relaxed and enjoying 
using the language. It may be said that college students, unlike children, having grown up, are not eager to play the games in the case of relaxing. But, in fact, adults sometimes might be found more nervous than children when they face new things like playing a new game.College students are more enthusiast about losing their faces even though as a sense of knowing their current age. In this sense, they do need games or any other activities that help them relaxed and innocent like children to the new language without being afraid of making mistakes (Zhu, 2012).

\section{The Definition of Codenames Game and its Procedure}

One of the media that English teachers can use in the classroom is cards. With cards, students feel excited to play in the form of English vocabulary words. This study uses game cards to help students more pleasant within some instructional rules. The name of the game cards is codenames games. Codenames game or spy game is an adapted game that we modified from a virtual game based on the classic and famous board game created by Vlaada Chvátil which is the name Codenames, too. In Spies, two teams namely; red and blue, try to compete with each other to get the score and avoid losing the game. This game contains several cards in which each card has written vocabulary in a word. This game is an instant hit whenever we bring it out and with whomever, we play with because codename game is easy to bring in the classroom, yet engaging the game with students has a difficult enough strategy to make them interest. Every time when we play this game, both teams have a path to win up until the very end of the game. The 8 or 9 codenames teams need to come up with which is a definite sweet-spot. This game provides never lasts too long for one team to really get out ahead of the other. For the replay of the game, hundreds of cards combined with a modular grid and a four-way key card provided. No two games will ever be the same in codenames game. This means that the game will stretch the players' minds every single time.

In the procedure of playing the codenames game in teaching vocabulary, some educational aspects of the game deserve to be mentioned. After the game is completely done, the teacher can mediate an interactive discussion within 
students in which as the masters and players. The students are offered the opportunity to justify their choices when they were playing the game. Commonly, no more than fifteen or twenty minutes are required to have an interactive discussion within each team consisting of three students (as one master and two players). During the discussion session, the teacher is possible to activate students' conceptual knowledge in an informal and more relaxed way, which is fundamental for the promotion of meaningful and contextual learning. Within discussion in the form of conversation ideally helps students develop their oral communication skills, which are useful in both academic life and at work (Souza, Morais \& Girardi, 2018). Therefore, if this game is played in some frequent time, the students, without no doubt are in a circle of developing their new vocabularies together with their friends.

\section{Method}

This study was carried out using qualitative research in the form of a classroom action research design. The qualitative research approach was chosen because this study relied on text and image data, have unique steps in data analysis, and draw on diverse designs (Creswell, 2014). Within the execution of this study used qualitative research, the writers tended to gain the data in the field of the site where the students as the participants experience the problem in enriching their vocabulary. Thus, the writers gathered information like Creswell (2014) suggested by actually talking directly to people and seeing them behave and act within their context.

While a classroom action research design was also used in this study. According to Burns (2010), a classroom action research relates to the ideas of 'reflective practice' and the teacher as researcher. In Action research, self-reflective, critical, and systematic approaches are explored into our own teaching contexts. During conducting action research, the teacher can be an investigator or explorer towards the teaching context, or she/he becomes one of the participants at the same time. Within the use of classroom action research, this study's aim is to improve the quality of learning in the classroom by developing a teaching media facilitated in a form of codename game.In addition, in a classroom action research design, Burns (2010) also adapted the steps of action research from Kemmis and McTarggart (1988) namely; i) Planning, a phase which the writer identify a problem or issue and develop a plan of action in order to bring about improvements in a specific area of the research context where the kind of investigation and the potential improvements are considered; ii) Action, a phase that involves some deliberate interventions into the teaching situation as the questions and assumptions of the current situation; iii) Observation, a phase which involves observing the effects of the action and documenting the context, actions, and opinions as data collection; and iv) Reflection, a phase to reflect on, evaluate, and describe the effect of the action. 
This research was conducted in the class of the English Language Department of IAIN Pekalongan in Pekalongan City, where the writers taught. The object of the study is the third-semester students majoring in English Language Education, IAIN Pekalongan in the academic year of 2018/2019. The writers involved third-semester students.

To gain the data of this study, the writers conducted two types of instruments, namely; 1) the observation instrument which is used to obtain data about student learning motivation and 2) the interview instrument. The use of observation helps the writers enable us to see and look directly what happens in the real-world as Cohen et al. (2007) said that observation offers an investigator the opportunity to gather 'live' data from naturally occurring social situations. So, using observation, the writers carefully prepared the indicators, which consist of five points covering work, thinking, curiosity, interest, and competition. In addition, to support answering the writers' questions, the interview instrument is also needed. This study used a semistructured interview which according to Nunan (1992) the interviewer has a general idea of where he or she wants the interview to go, and what should come out of it, but does not enter the interview with a list of predetermined questions. In other words, the writers can enable to gain the data directly from participants regarding expressions and views of the life situations in the form of having a conversation rather than asking and answering questions formally. So, the writers already have considered three indicators as guidance in conducting the interview, which includes knowing the extent to which students understand English vocabulary, knowing whether learning class vocabulary is meaningful and easy to understand, knowing whether this media card game is effective for adding new vocabulary.

\section{Result and Discussion}

Regarding the aim of this study, which was to provide the information of the implementation codenames game helping English department students of IAIN Pekalongan to enrich and build their vocabulary in a fun way using game cards, this part displays the result of this study.

Based on the data collection taken from observation and interview instrument, this study resulted in a cyclical process in a classroom action research as Burns' adaptation steps (2010) from Kemmis and McTarggart (1988) suggested and displayed the discussion.

\section{Planning}

Many learners in English as a foreign language, particularly in English department students have a weakness mainly in memorizing the English vocabulary. The students' vocabulary knowledge is still not well-established and limited. When students are asked to make sentences by their lecturer, most of 
them often use a very common vocabulary. To reduce this problem, researchers have a breakthrough that can be used in English learning. The breakthrough is using one vocabulary strategy by playing the vocabulary game.The vocabulary game that the writers suggested was the codename games. According to the writers, this game is considered suitable and proven to be successful for English department students because basically the students still need exposure learning to develop vocabulary in a meaningful and fun way. So, the writers employed this game by making strategic planning that enables the writers to engage the students within the implementation.

The strategic planning started with preparing cards that are used as a learning media for vocabulary. Then the are required looking for vocabulary that is often used, particularly in an academic reading text by selecting the most suitable words in a rough concept.The next step was looking at the relationship between the vocabulary on cards and the procedures on how to play. The final step was required by creating interactive cards with the words and identified pictures on them.

\section{Actions (Implementing the Plan)}

The writers made the procedures and rules of the game that have been adjusted to the needs of the study so that the game players can develop and enrich their vocabulary through this game card. The steps are applied as follows:

Step 1: One team consists of four (4) people divided into two spymaster camps with one jury. Each spymaster camp has two members as the one who decided to guess a word and the other one who provided adequate clues.

Step 2: Each spymaster member is allowed to guess the vocabulary included in his area through the vocabulary map given by the jury. Only the recipient of the clue (spymaster) from each camp is allowed to see the map.

Step 3: The clue giver is only allowed to provide adequate clues using the English language related to the vocabulary on the card by considering the region of each spymaster.

Step 4: After knowing the word to be guessed, the guesser points to a vocabulary card that is supposed to be referred to by a spymaster.

Step 5: If the guesser mentions the correct vocabulary, then the judge closes the area with a spymaster identity card (red or blue card).

Step 6: If the guesser mentions the word in question, then the spymaster area is not closed with an identity card, and the chance to guess is diverted to the turn of the other camp.

Step 7: The game ends if the vocabulary stock in the map is successfully covered by one of the camps. So, the game will be won by a spymaster who first completely finished guessing vocabularies, which are all true answers. 
After the game was implemented,the writers saw the development of students' vocabulary knowledge. Through this game, students learned and enriched many new vocabularies. This is considered a good achievement. The students found that the codenames game was easier in helping to memorize vocabulary and to provide a framework incorporating the new words with information already known. Compared to implementing this game in the classroom, students become more excited and eager to learn new vocabulary. Expected within playing this game, students became motivated to develop their vocabulary knowledge, so they have a broad knowledge and are not easily satisfied with what they have learned. The two documentations show the implementation of the game played by students.

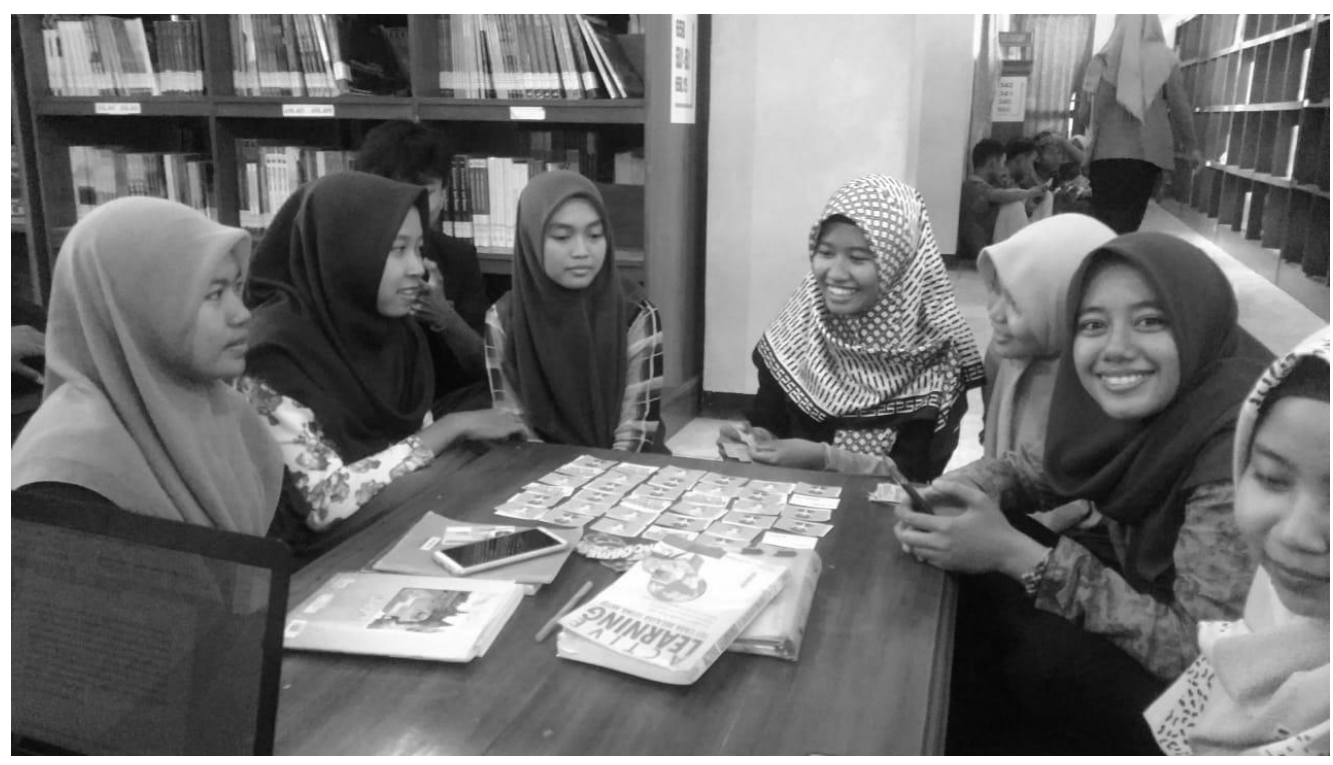

Figure 1. The students started to play the codenames game 


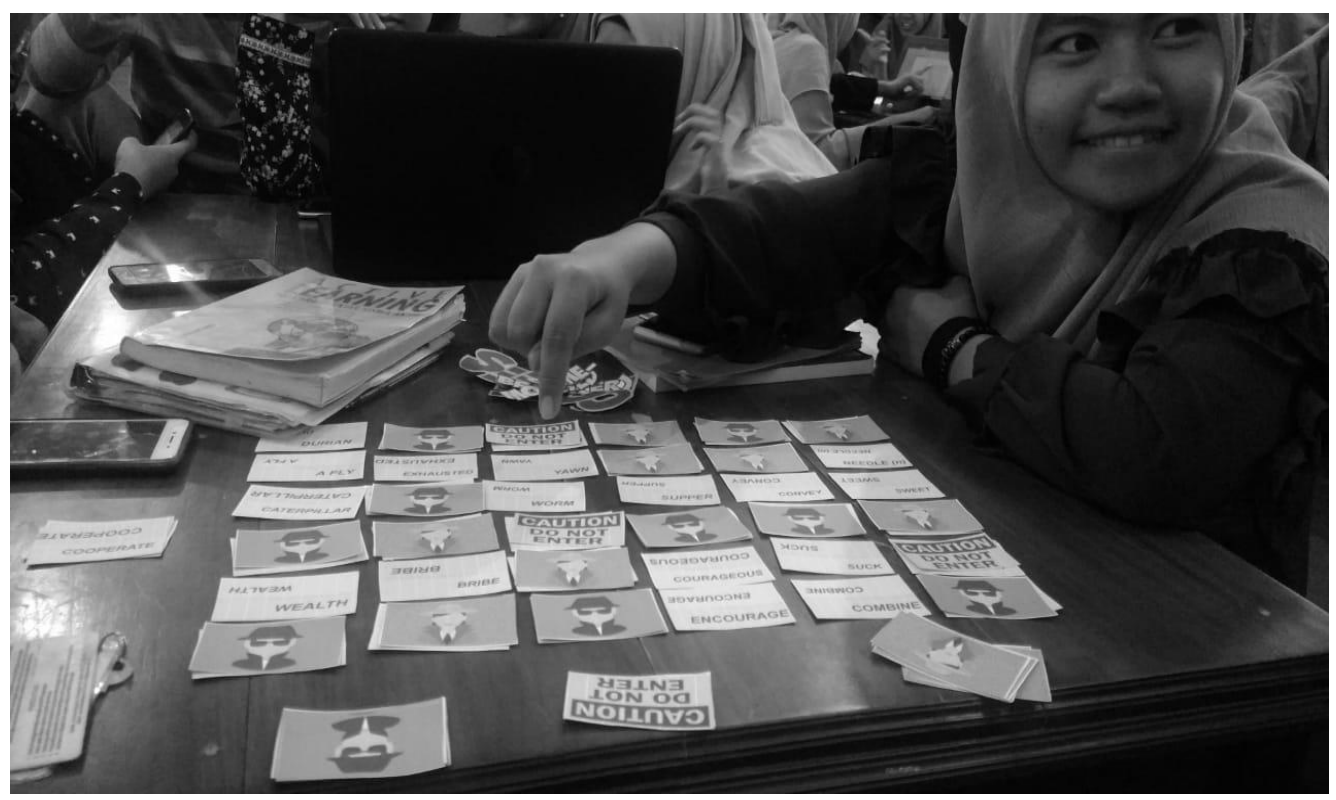

Figure 2. The students played the codenames game in a team

\section{Observation}

Observation and participants' feedback highlighted the value of a provocative question format and the metaphor of a card game. On the first observation, it was found that during supervision, students had difficulty finding a learning strategy that could develop their vocabulary knowledge. Students who frequently use memorization techniques are in an effort to increase their vocabulary; of course, they could not really do it because of not their own initiative to enrich vocabulary, but because of the demands of the assignment in some certain subjects asked by the lecturers. As a result, students are more likely to become easy to forget the vocabulary got from the memorization process. This happens mainly because the memorizing words that students do is under compulsion of the subject's requirement. Here, the important point to underline is that when students used conventional vocabulary learning strategy, their interest and motivation could not potentially be gained so they seem less attractive and enthusiast unless there is found a technique which is alternatively to create a different variety.

In the first sub-observation holding a vocabulary technique to employ, students determine a comfortable place to play the codenames game. It was started with the first game activity which was carried out in a classroom that is free from formal learning activities. In this playing game activity, there were seven students present. Five students were players of the game, while the other two students became spectators watching this game. Of the five players, one judge was chosen objectively, and then four players automatically chose their partner to be matched related to the game requirement. After determining the 
playing partner then they are given the direction and rules of the game from the jury. At first, these students seem to get a little confused with the rules of the game, so the direction and the rules of the game were repeated until they really understood well.

After the students as the players have understood well about how to play the codenames, they started playing the game based on the instructions. Firstly, each team gives clues about general things. Once when students were asked to provide adequate clues to guess the word, they seemed did not successfully deliver the ideas. This was caused that the student as the player was not yet accustomed to delivering their ideas within making the sentences. In addition, the students always found unknown words that they did not find them in lecturing classes. And sometimes students spontaneously say a few words in Indonesian. But after that, the jury allowed all players to look up the words in a dictionary when they felt it difficult to say something using English words.

From the delivery process, the writers looked at all the game parts in playing activities that could help students enrich and develop their vocabulary. Besides, the game trained them to practice in a peer group by not only verbally saying and interacting using English and also engaging their relationship. Students who became guessers also had difficulty in guessing from the given clues; this was due to the fact that the logger was unfamiliar with a few words conveyed by the provider. Sometimes the guesser asked his colleagues about clues in unknown words provided by the giver of the opponent. The reason why some words were unknown to the guesser was that due to students' listening skill is considerably still poor. So, the guesser tried to incorporate the new vocabulary containing the foreign terms and unknown words in clues relevant to vocabulary knowledge that they had.

Every team always had a discussion and used strategies to be able to guess and give difficult answers. Basically, it showed competition and interaction for each player. After conducting an observation throughout the implementation of the game, students felt challenged with the need given by each team. They looked very enthusiastic and enjoyed playing the game. It could be proved by seeing students' expressions when they succeed in guessing every code that was given. They also regretted when they failed to guess the code given. From their emotional state, it is expected that the players can leave an impression that makes them always easy to memorize and remember the important things and words vocabulary by playing this game.

\section{Critical and Self-Critical Reflection}

After watching as the game progressed, researchers interviewed the players two days later. The interview questions included the development of the vocabulary obtained by students after playing the codenames. As we have seen 
in the result, students agreed that the codenames game is effective to enrich and develop their vocabulary. This was evidenced by the ability of those who still remembered the new words when they have been given a clue by the opponent. And then the important thing here was that they still remember the correct answer shown by the judge when they guessed incorrectly.Finally, from their statement, students assumed that the codenames game is very meaningful to build teamwork and good communication between players, train them to compose words that were not usually practiced in the classroom, and could help experience for listening skills.

The present study focused on the use of codenames games as a way of vocabulary delivery. After a cyclical process in a classroom action research, the writers came to an end of the implementation of the codename game and got the data from the participants through observation. Having collected the data, the process of data analysis was conducted by the writers to come up with the results. It was found that vocabulary learning through the use of codenames game proved as an activity providing entertainment, amusement and competitive activity in which the players in a collaboration team within the procedures and rules of the game.

Since the present study was based on a classroom action research design, the survey part was done by an attitude of the semi-structured interview. The students' attitude was drawn to do the analyzing of data collection. The data analysis showed a positive attitude in participants towards using codenames games as a way of memorizing the words.

When the findings of the present study were compared with the findings in the literature using card game, it was revealed that those of this study fit $\mathrm{n}$ the previous related studies (e.g. Reza, Mohammad, \& Sayed, 2015; Luu Trong Tuan, 2012 \& Robert \& Laura, 2017). These studies proved that students prefer to use cards game for learning vocabulary because it could facilitate memorizing words in a more fun way.

\section{Conclusion}

In conclusion, the use of codenames game could enrich students' vocabulary and be as an alternative entertainer learning English words in a more fun way. Due to the boredom of the memorization technique that most students experienced in lecturing class, the codenames game then could facilitate to memorize the words. At first, when conducting an observation in implementing the codenames game, the students seem to get a little confused with the rules of the game. So, the direction and the rules of the game were repeated to encounter students' understanding. After the game was played, the students felt challenged by the need given by each team. They looked very enthusiastic and enjoyed playing the game. It could be proved by seeing 
students' expressions when they succeed in guessing given code.The writers, however, decided that this result still needs enlightenment so that is why the writers are open to other possibilities of the codenames gameor any other card games that can be used in vocabulary learning strategy and be more explored in many ways to reach the next milestones 


\section{References}

Annisa, Lutfiana Ilma and Rohani. 2015. Developing Quartet Card Games for TeachingVocabulary. Journal of English Language Teaching. Vol. 4. No. 1.

Burns, A. 2010. Doing Action Research in English Language Teaching: A Guide for Practitioners, New York: Routledge.

Celce-Murica, M. 1989. Discourse analysis and grammar instruction. Annual Review of Applied Linguistics, 11, 135-151. In D. Crookal (Ed), Simulation, Gaming, and Language Learning, 1991, New York.

Celce-Murcia, M. 2001. Teaching English as a Second or Foreign Language. $4^{\text {th }}$ ed. Boston: Thomas Learning

Chan, Y. C., \& Lin, L. C. (2000). Competitive and cooperative games in EFL elementary school classroom. Proceedings of ROCMELLA 2000, National Taipei University of Education, 123-147.

Cohen, L., Manion, L., Morrison, K. 2007. Research Method in Education. $6^{\text {th }}$ ed. New York: Routledge.

Creswell, J. W. 2014. Research Design: Qualitative, Quantitative, and Mixed Methods Approaches. $4^{\text {th }}$ ed. California: SAGE Publications, Inc.

Honarmand, R. et al. 2015. The Effect of Game Tic Tac Toe and Flash Cards on Zero Beginners' Vocabulary Learning. International Journal of Educational Investigations. Vol. 2, No. 3: 27-41, 2015. Retrieved from www.ijeionline.com.

https://www.boardgamemechanics.com/blog/codenames.

Jiang, L. (2008). The use of games in teaching children English. Unpublished master"s thesis, Shandong University, Shandong province, China.

Kuo, Y. L. (2008). The effect of games in fifth graders' English speaking ability in an elementary school in Taipei County. Unpublished master"s thesis, National TaipeiUniversity of Education, Taipei, Taiwan

Nikoopour, J and Azin Kazemi. 2014. Vocabulary Learning through Digitized \& Non-Digitzed Flashcards Delivery. International Conference on Current Trends in ELT. Procedia - Social and Behavioral Sciences 98 (2014) 1366 - 1373.

Nunan, D. 1992. Research Methods in Language Learning. Cambridge: Cambridge University Press.

Pound, L. (2005). How children learn. London: Step Forward Publishing, Ltd. 
Rahmasari, B. S. The Use of Flashcards in Teaching Vocabulary at Fourth Grade Students of SDN Sukosari 02 Dagangan Madiun. Jurnal Edutama. Vol 3, No. 1.

Richards, J. C. \& Rodgers, T. S. 2001. Approaches and Methods in Language Teaching. $2^{\text {nd }}$ ed. Cambridge: Cambridge University Press.

Rixon, S. (1981). How to Use Games In Language Teaching. London: Macmillan Publishers Ltd.

Robinson, K. (1960). English teaching in south-east Asia. London: Evan Brothers, Ltd

Scout Thornbury. 2002.How to Teach Vocabulary, London: Longman.

Sheridan, R., \&Laura Markslag. 2017. Effective Strategies for Teaching Vocabulary: An Introduction to Engaging Cooperative Vocabulary Card Activities. PASAA. Vol. 53 January - June 2017.

Slavin, R. E. (2006). Educational psychology (8th ed.). Boston MA: Allyn and Bacon.

Souza, P. V. S.et al. 2018. Spieas: An Educational Game. Brazil: IOP Publishing.

Tuan, L. T. 2012. Vocabulary Recollection through Games. Theory and Practice in Language Studies. Vol. 2, No. 2, pp. 257-264.

Wang, Ying-Jian Wangetal. 2011. Investigating the Impact of Using Games in TeachingChildren English. International Journal of Learning \& Development. Vol.1. No.1.

Zheng, M. H. (2008). Game in the primary English teaching. Unpublished masteres thesis, Nanjing Normal University, Nanjing province, China

Zhu, Deguang. 2012. Using Games to Improve Students' Communicative Abilitty. AcademyPublisher. Vol. 3. No. 4. 